\title{
PALEOKARST CRUST OF ORDOVICIAN LIMESTONE AND ITS CAPABILITY IN RESISTING WATER INRUSHES IN COAL MINES OF NORTH CHINA
}

Lin Mou, Gongyu Li

Xi'an Research Institute of China, Coal Technology \& Engineering Group Corp., Xi'an, Shaanxi 710054, China, moulin@cctegxian.com,ligongyu@msn.com

\begin{abstract}
With increase in mining depth of the CarboniferousPermian coal seams in North China, it is particularly important to study the heterogeneity of karst development in the underlying Middle Ordovician limestone and determine any impermeable strata that may prevent the pressurized karst water from bursting into coal mines. Detailed analysis of the exploratory borehole data suggests presence of a paleokarst crust at the top of Middle Ordovician Fengfeng Formation. Because of its mechanical strength and low permeability to water, the paleokarst crust can function as an additional waterresisting layer. This paper takes Sihe Mine of Shanxi Province as an example to study the geotechnical and hydrogeological characteristics of the paleokarst crust. Incorporation of this additional hydrological barrier led to more minable coal seams in the coalmine.
\end{abstract}

\section{Introduction}

Middle Ordovician limestone and CarboniferousPermian coal seams are widespread in North China, as shown in Figure 1. Mining of the coal seams in the past few decades has led to multiple theories and techniques of evaluating the pressurized water from the limestone into underground mining areas. These theories emphasize the potentiometric pressure in the Middle Ordovician limestone and the aquifuge between the coal seams and the Middle Ordovician limestone. The term "aquifuge" is defined in this paper as an impermeable body of rock which contains no interconnected openings or interstices and therefore neither absorbs nor transmits water and it is interchangeable with the term "aquiclude." The most commonly used water inrush coefficient is defined by:

\section{$\mathrm{T}=\mathrm{P} / \mathrm{M}$}

where $\mathrm{T}$ is the water inrush coefficient; $\mathrm{P}$ is the potentiometric pressure; and $\mathrm{M}$ is the thickness of aquifuge. The greater the water inrush coefficient is, the more likely occurs a water inrush. The potentiometric pressure is typically measured at monitoring wells in the Middle Ordovician limestone while the limestone has been treated as a unified aquifer system. Determination of the aquifuge thickness is less definitive but it is an equally important parameter. Similar approaches are used in other countries (Verbovsek and Veselic 2008; Hawkins and Aljoe 1992).

With increase in mining depth of the CarboniferousPermian coal seams, the potentiometric pressure of the Ordovician groundwater becomes higher, indicating a higher risk of water inrush. It is particularly important to study the heterogeneity of karst development in the underlying Middle Ordovician limestone and determine any impermeable strata that may prevent the pressurized karst water from bursting into coal mines. Detailed analysis of the exploratory borehole data suggests presence of a paleokarst crust (hereinafter referred to as crust) at the top of Middle Ordovician, which is often referred to as the Fengfeng Formation (Figure 2). The enormous variation in water-resisting capacity makes recognition and application of the crust less straightforward in coal mining.

\section{Studies on Paleokarst Crust}

Studies by Li and Wang(1997)indicate that the Early Carboniferous strata were re-deposited after 150 million years (Ma) of the Middle Ordovician, which resulted in the ubiquitous Bauxite mudstone. The top Middle Ordovician was further compacted and any fractures would have been filled by the overlying fragments of mudstone. Large voids were difficult to exist because of weight of the overlying strata ( $\mathrm{Li}$ and Wang 1997; Li et al. 1997). A schematic diagram is shown in Figure 3 to illustrate this concept. Between 2009 and 2011, Bai and others (2009a; 2009b; 2010; Miu and Bai 2011) published a series of research findings about mining above the Fengfeng Formation in the Lu'an Mining Area and Xuzhou Ming Area and formed a new concept for controlling water hazards and utilizing water resources. 


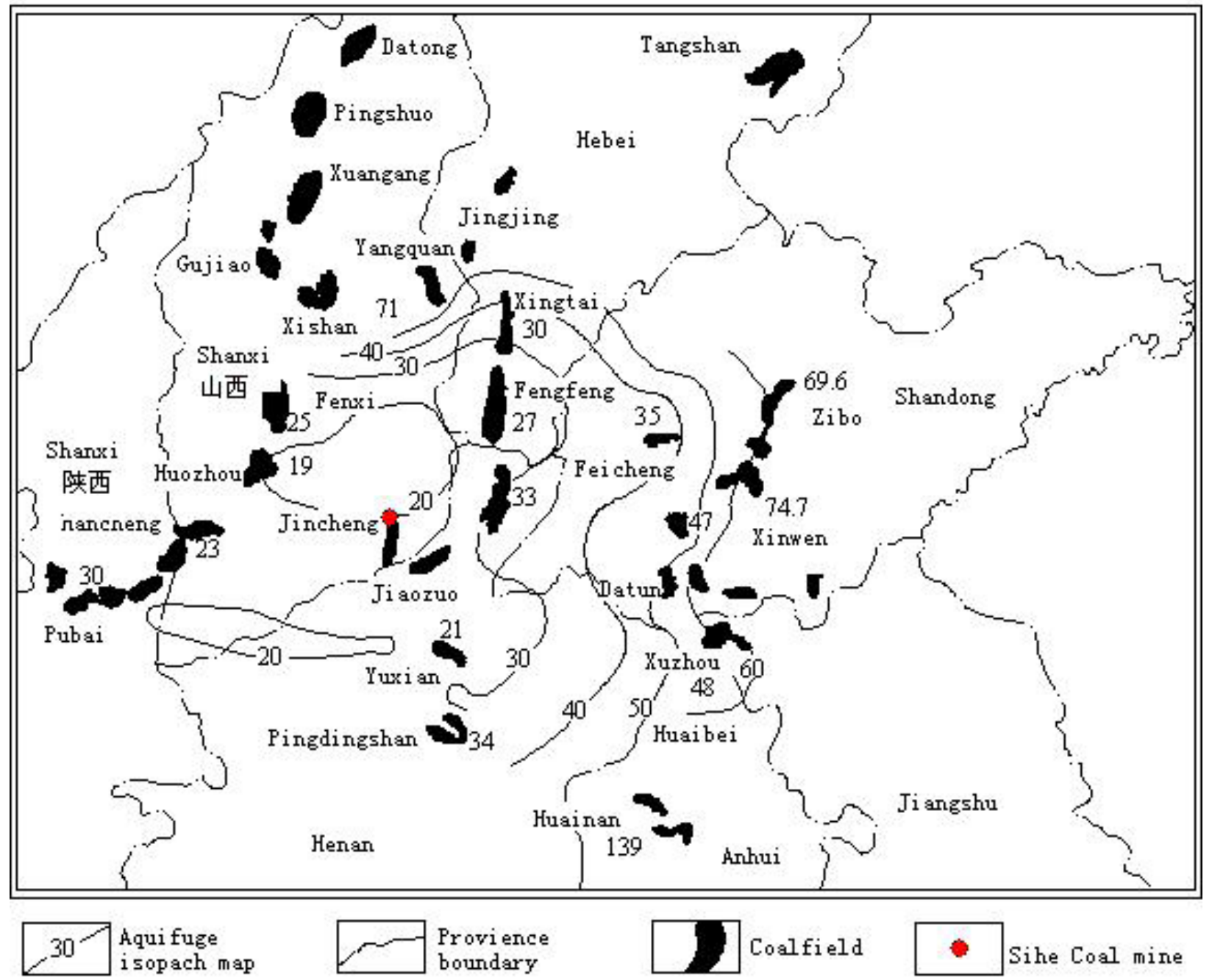

Figure 1. Distribution of coal resource and aquifuge in North China.

Based on thin section analysis of rock samples, X-ray fluorescence spectrometry, and rock microstructure analysis, Wang and Bai (2009) analyzed the lithology, karst pore structure and distribution in the Fengfeng Formation in Zhangcun Mine of Lu'an Ming Group, Shanxi Province. Their results show approximately 140 meters (m) aquifuge in total at the top and bottom of the Fengfeng Formation. Bai and others (2009) proved the presence of the aquifuge by statistic analysis of data collected in Shandong, Shanxi, and Hebei Provinces.

The presence of aquifuge may explain why the water inrush did not occur in the theoretically predicted water bursting areas, while it occurred in the anticlinal development areas (Wang and Bai 2009). Fu and others (2010) took samples from the Fengfeng Formation in Wang Jialing Mine in Shanxi Province and divided the Fengfeng Formation into four zones:
- Weathered and leached zone

- Upper section with gypsum

- Thick micrite section

- Lower section with gypsum

Of the four zones, the lower section appears to have a strong water-resisting capacity.

\section{Characteristics of Paleokarst Crust at Sihe Mine}

Sihe Mine is in Shanxi Province (Figure 1), which is a large anthracite base with an annual production of 1,200 million tons. The average thickness of the Fengfeng Formation is approximately $100 \mathrm{~m}$. The distance between the lower coal seams and the Middle Ordovician limestone is approximately $20 \mathrm{~m}$. The water pressure exerting on the coal seam floor ranges from 1 to 3 megapascal (MPa). The potential of 


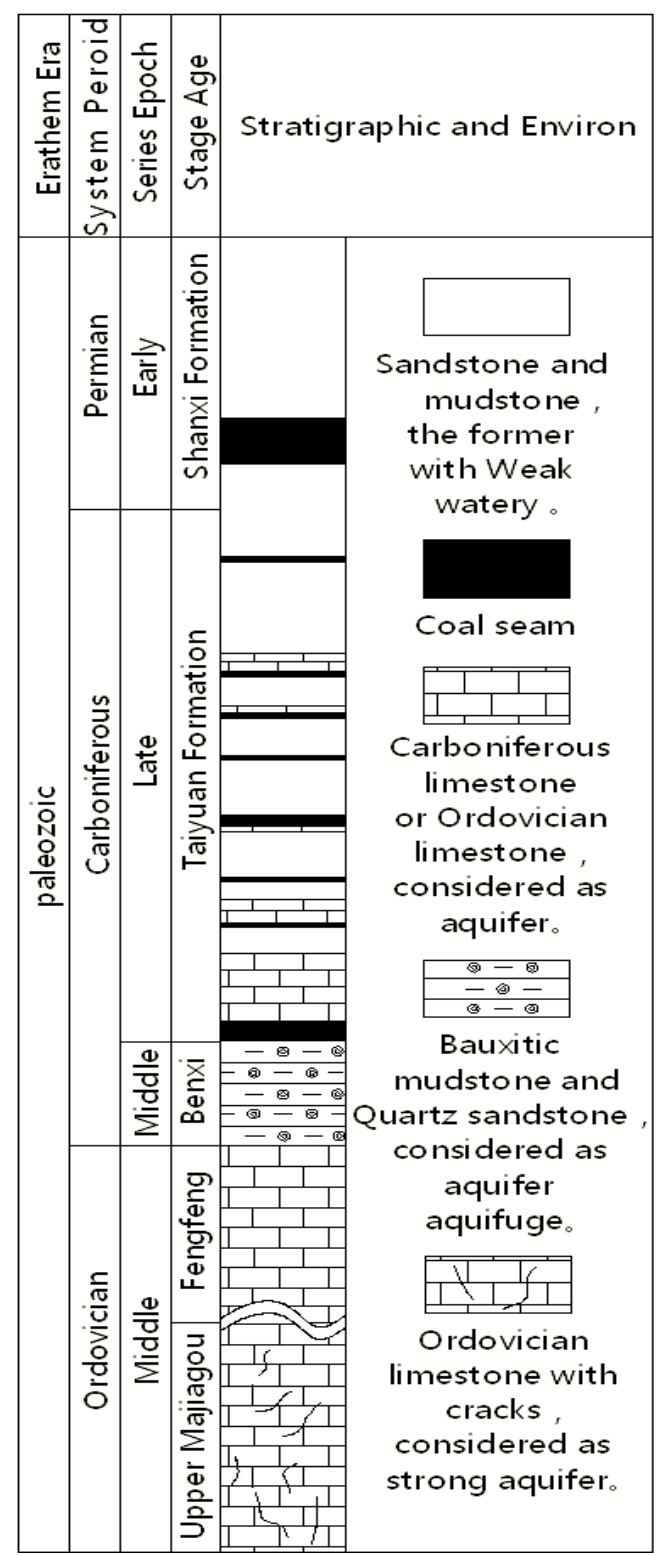

Figure 2. Typical geological column in North China coal fields. water inrush has become a key factor restricting its sustainable production at the mine.

\section{Lithology of Fengfeng Formation}

Figure 2 shows the relationship between the coal seams and the underlying limestone formations. The Fengfeng Formation at Sihe Mine consists of cyclic deposition of pure limestone and argillaceous limestone with variable thicknesses. It does not constitute a water-resistance layer in its unaltered state. This cyclic depositional structure is common in the middle of the Fengfeng Formation with a thickness between 20 and $50 \mathrm{~m}$. The top $20 \mathrm{~m}$ of the Fengfeng Formation is pure limestone which is the country rock for the paleokarst with any fractures filled with calcite and weathering residuum. This altered top section of the Fengfeng Formation provides a geologic barrier to groundwater flow.

\section{Fractures in Fengfeng Formation}

Three types of fractures were observed in the Fengfeng Formation: cross joints, inter-laminar joints, and microstructural fractured fractures (Figure 4). The upper part of the Fengfeng Formation mainly develops the microstructural fractures with the joints being secondary. The lower part of the Fengfeng Formation is a water-bearing region and the paleo-karstification and weathering is not as obvious as the top part. The main form of fractures is either oblique cross joints or inter-laminar joints.

\section{Filling materials}

Physical and chemical weathering over $150 \mathrm{Ma}$ has produced a large amount of breccia cemented with calcite, the weathering residues, or argillaceous filler. As shown in Figure 5, the high extent of cementation and filling in breccia or fractures makes the paleokarst crust in the Fengfeng Formation possess strength and water-

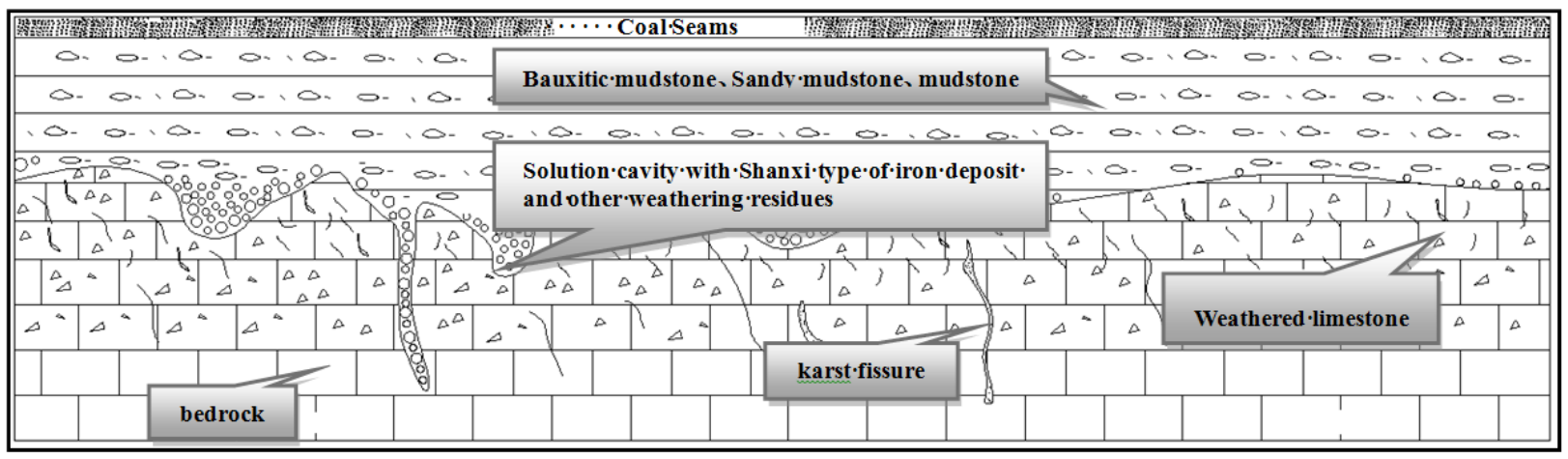

Figure 3. Palaeokarst profile in Fengfeng Formation. 


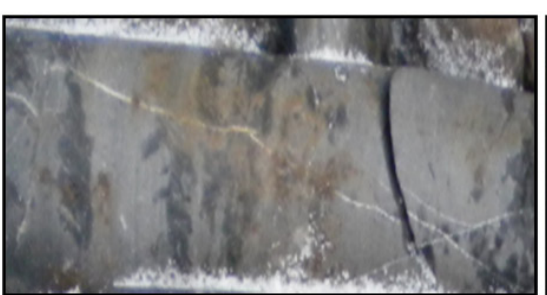

a. Oblique cross joint

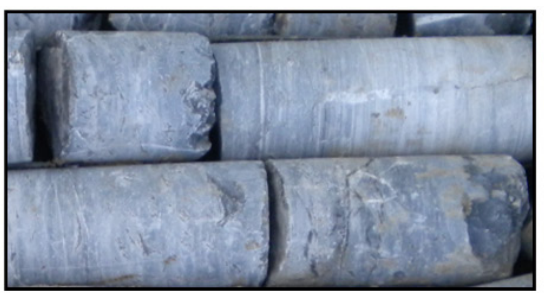

b. Inter-laminar joint

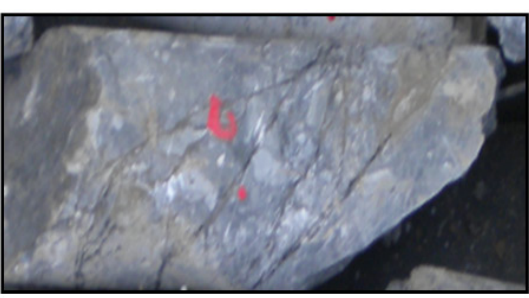

micro-structural fractures

Figure 4. Three different types of fractures in Fengfeng Formation.
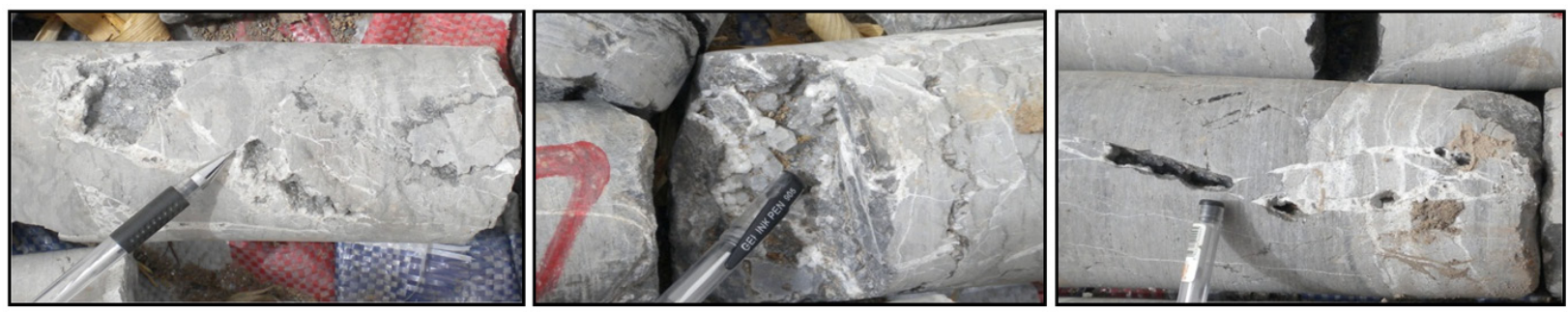

Figure 5. Cemented fractures in Fengfeng Formation.

resisting capacity. The characteristics of geologic barriers in preventing water inrushes are discussed in Zhou and $\mathrm{Li}$ (2001).

\section{Water-resisting capacity}

Pumping tests, flow-rate logging, chemical analyses of groundwater, and water-pressure tests were conducted to determine the water-resisting capacity and spatial distribution of the aquifuge in the Fengfeng Formation. The hydrogeological characteristics of the Fengfeng Formation were then compared with those of the underlying upper Majiagou Formation (Figure 2), which is often considered as a strong aquifer.

\section{Results of water-pressure tests}

The water-pressure tests were conducted in thirteen boreholes. The technique of conducting the pressure tests is detailed in Zhou and Li (2001). The test results show that the top $35 \mathrm{~m}$ of the Fengfeng Formation has an extremely poor permeability ranging from 0.00002 to $0.00024 \mathrm{~m} / \mathrm{d}$, which indicates that this part of the stratum has a certain water-resisting capacity. The water pressure in the Ordovician limestone gradually decreases in the underlying stratum. The thickness of this part is $8.6 \mathrm{~m}$ and the water pressure drop is $3.27 \mathrm{MPa}$. As a result, the water resistance coefficient is approximately $0.38 \mathrm{MPa} / \mathrm{m}$.

\section{Hydrogeogical Properties of Fengfeng Formation Drilling fluid loss}

Of seventeen Ordovician hydrogeological boreholes drilled in the Fengfeng Formation in Sihe Mine, fourteen boreholes lost drilling fluid at normal rates from 0.1 to
$1 \mathrm{~m}^{3} / \mathrm{h}$ and only three encountered significant loss of more than $1 \mathrm{~m}^{3} / \mathrm{h}$ in the lower segment of the Fengfeng Formation. Of the sixteen boreholes drilled through the upper Majiagou Formation,eight boreholes' consumption of drilling fluid was at normal rates and significant or massive loss occurred in the other eight boreholes in the middle segment of the upper Majiagou Formation. The difference of drilling fluid loss between the Fengfeng Formation and upper Majiagou Formation suggests that the fractures in the Fengfeng Formation might have been filled and the formation is not as conducive to water flow and storage.

\section{Pumping test results}

Table 1 lists the thirteen boreholes in which pumping tests were conducted in both the Fengfeng Formation and the upper Majiagou limestone. The specific capacity of the Fengfeng Formation is between 0.0009 and 0.0058 1/s.m. Those values are two to three orders of magnitude smaller than those of the upper Majiagou Formation combined, which ranges from 0.0005 to $0.594 \mathrm{l} / \mathrm{s} . \mathrm{m}$. In addition, the water level of the Fengfeng Formation is apart from that of the upper Majiagou Formation, with a difference ranging from 1.1 to $37.6 \mathrm{~m}$. The tests have proved that the water abundance of the Fengfeng Formation is much weaker than that of the upper Majiagou Formation.

\section{Hydrogeochemical test results}

Figure 6 shows the Piper diagrams based on the water samples collected in these thirteen boreholes at which the pumping tests were conducted. The main anion in the Fengfeng Formation is SO42-, secondly CL-, while the content of HCO3- is little. The main cations 
Table 1. Result of Ordovician limestone pumping tests

\begin{tabular}{|c|c|c|c|c|c|c|}
\hline & \multicolumn{2}{|c|}{ Comparison of water level } & \multicolumn{2}{c|}{ Comparison of Specific Capacity } \\
\cline { 2 - 7 } Borehole & $\begin{array}{c}\text { Fengfeng } \\
\text { Formation }\end{array}$ & $\begin{array}{c}\text { Majiagou } \\
\text { Formation }\end{array}$ & Difference & $\begin{array}{c}\text { Fengfeng } \\
\text { Formation }\end{array}$ & $\begin{array}{c}\text { Majiagou and } \\
\text { Fengfeng } \\
\text { Formations } \\
\text { Combined }\end{array}$ & $\begin{array}{c}\text { Ratio of } \\
\text { Combined and } \\
\text { Fengfeng } \\
\text { Formation }\end{array}$ \\
\hline SWY2 & 555.8 & 521.2 & 34.6 & 0.000942 & 0.000859 & 0.9 \\
\hline SC2 & 449.7 & 483.5 & 33.8 & 0.001 & 0.188 & 188 \\
\hline GZ & 450.9 & 481.5 & 30.6 & 0.00588 & 0.0366 & 6.2 \\
\hline SWY1 & 482.4 & 493 & 10.6 & 0.0026 & 0.144 & 55.4 \\
\hline SB1001 & 511.4 & 488.79 & 22.61 & 0.000477 & 0.13947 & 292.4 \\
\hline SB1002 & 546.54 & 508.94 & 37.6 & 0.00299 & 0.112379 & 37.6 \\
\hline SB1003 & 544.92 & 513.54 & 31.38 & 0.004489 & 0.06624 & 14.8 \\
\hline SB1004 & 495.46 & 478.75 & 16.71 & 0.004721 & 0.044552 & 9.4 \\
\hline SB1005 & 466.84 & 477.75 & 10.91 & 0.0004 & 0.00052 & 1.3 \\
\hline SW2 & 497.7 & 513.1 & 15.4 & 0.00305 & 0.00324 & 1.1 \\
\hline SWY3 & 488.7 & 487.6 & 1.1 & 0.00478 & 0.594 & 124.3 \\
\hline SC3 & 489.2 & 487.1 & 2.1 & 0.00435 & 0.0268 & 6.2 \\
\hline SW1 & 512 & 488.4 & 23.6 & 0.00403 & 0.302 & 74.9 \\
\hline
\end{tabular}

in the Fengfeng Formation are $\mathrm{Ca} 2+$ and $\mathrm{Mg} 2+$. The composition of mixed samples of the Fengfeng and Maijiagou Formations is quite different. The main cation is $\mathrm{Ca} 2+$, and the main anion is $\mathrm{SO} 42-$, followed by $\mathrm{HCO} 3-$ . These observations indicate that the Fengfeng Formation is in a more reductive environment than the Majiagou Formation. The water in the Fengfeng Formation has poor circulation, which is evidenced by the lack of HCO3-, a common cation in good groundwater flow conditions.

\section{Flow rate logging results}

Based on the flow rate logging results in six boreholes, no flow date could be obtained in the Fengfeng Formation because of its poor water yield. In comparison, obvious flow rate data were obtained in the Majiagou Formation. In addition, more boreholes showed greater water flow rates in the middle of the Majiagou Formation than in the top zone.

\section{Thickness of aquifuge in Fengfeng Formation}

In North China, the water abundance of an aquifer is often divided into four classes based on specific capacity:

$$
\begin{array}{ll}
\text { - } & >5.0 \mathrm{l} / \mathrm{s} . \mathrm{m} \text { - very strong } \\
\text { - } & 1.0-5 \mathrm{l} / \mathrm{s} . \mathrm{m} \text { - strong } \\
\text { - } & 0.1-1.0 \mathrm{l} / \mathrm{s} . \mathrm{m} \text { - moderate } \\
\text { - } & =0.1 \mathrm{l} / \mathrm{s} . \mathrm{m} \text { - weak }
\end{array}
$$
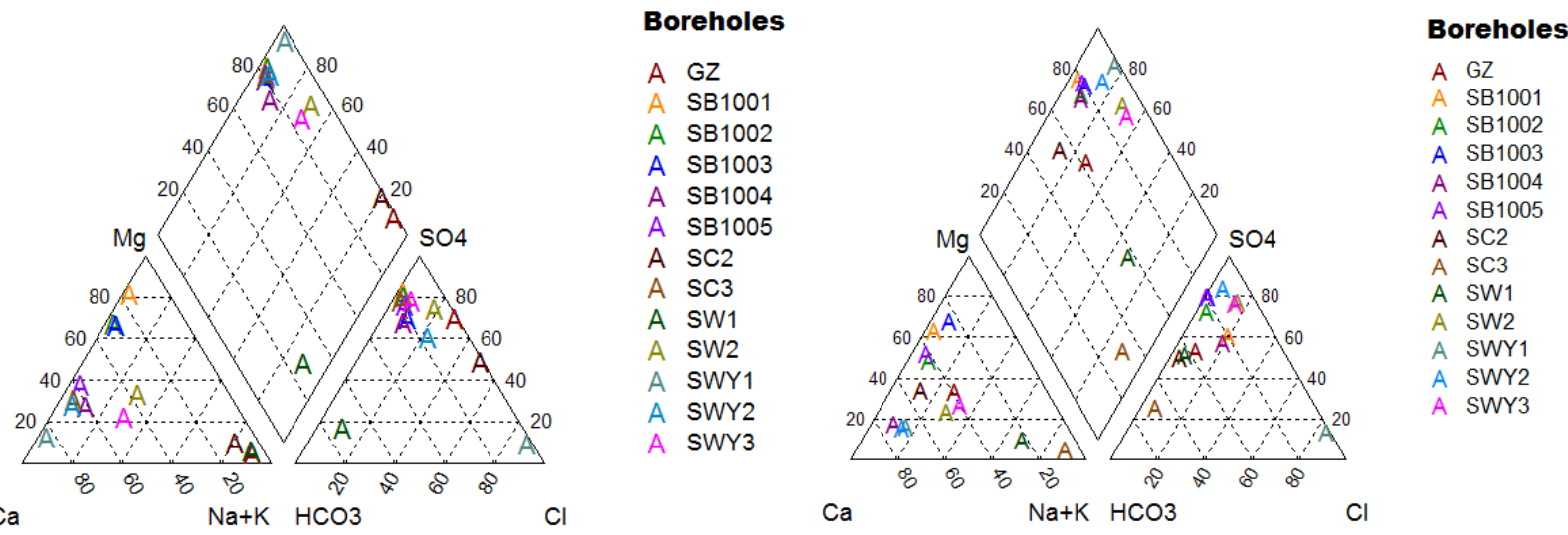

Figure 6. Piper diagrams for groundwater in Fengfeng Formation (a) and Majiagou Formation (b). 
The specific capacity of the Fengfeng Formation is between 0.0009 and $0.0059 \mathrm{l} / \mathrm{s} . \mathrm{m}$, which falls in the category of a weak aquifer or relative water-resisting aquifuge. The thickness of relative aquifuge ranges from 35 and $70 \mathrm{~m}$ based on the summary statistics.

\section{Conclusions}

Significance of the water-resisting ability of Ordovician limestone for mining above an aquifer

1. Problems of mining above an aquifer are increasingly serious in North China. In Sihe Mine for example, after considering the relative aquifuge, more than 90 million tons of coal resources are considered to be not threatened by the underlying pressurized water. Careful analysis of the potential water-resisting capacity of the Fengfeng Formation helps understand the real conditions when mining above the aquifer. The Ordovician limestone may not be a unified karst aquifer system but consist of protective barriers. Recognition of the heterogeneous nature provides us with a new approach for evaluating water inrushes when mining above an aquifer.

2. Based on studies on the water-resisting capacity of the paleokarst crust in top part of the Middle Ordovician limestone, the paleokarst crust can be treated as an aquifuge with a thickness of 35-70 m in Sihe Mine.

3. When doing a study on the hydrogeological features of the Ordovician limestone, a multidisciplinary approach, such as water abundance, hydrochemistry characteristics, permeability of strata, and strata combination, is needed to make the most appropriate judgment.

4. The water-resisting capacity of the paleokarst crust in the coal fields of North China may be variable in different areas. In some areas it may not exist. However, recognition of the potential significance of the paleokarst crust may increase the coal production or lengthen the operation of a mine.

\section{References}

Bai Xiqing, Bai Haibo, Shen Zhihui. 2009. Relative strata impermeability in Ordovician top and risk assessment of water inrush from coal floor in xinyi coalfield. Chinese Journal of Rock Mechanics and Engineering 2: 273-280.
Bai Haibo, Mao Xianbiao, Wu Yu, Chen Zhanqing. 2009. Research on water-reserved mining with high water pressure under large-scale thrust-fault in Ordovician karst. Chinese Journal of Rock Mechanics and Engineering, 28 (2): 246-252.

Bai Haibo, Mao Xianbiao, Wu Yu, Yao Banghua, Tang Junhua. 2009. Research on simultaneous exploitation of coal and groundwater in Lu'an coalfield. Chinese Journal of Rock Mechanics and Engineering 28 (2): 395-401.

Bai Haibo, Yang Jianli, Wang Changshen. 2010. Research on limestone aquifuge in top Ordovician and its application in roadway excavated through graben faults. Journal of Mining \& Safety Engineering 27 (3): 322-329.

Fu Lei, Li Zhuangpeng, Xu Jinpeng, Li Junjie, Wang Pan-pan, Ji Qing, Ding Zhuo. 2010. Impermeability analysis of Middle Ordovician Fengfeng Formation in Wangjialing Coalmine. Coal Geology of China 3: 28-31.

Hawkins JW, Aljoe WW. 1992. Pseudokarst groundwater hydrologic characteristics of mine spoil aquifer. Mine Water and the Environment 11 (2): 37-52.

Li Ding-long, Wang Gui-liang. 1997. Several thoughts on Ordovician Limestone Karst Study in area of North China. World Geology 1: 60-65.

Li Ding-long, Zhou Zhian, Wang Guiliang. 1997. Approaching problems in karstic studying of Majiagou Limestion in area of North China. Geological Science and Technology Information 1: 23-28.

Miu Xiexing, Bai Haibo. 2011. Water-resisting characteristics and distribution rule of carbonate strata in the top of Ordovician in North China. Journal of China Coal Society 36 (2): 185-192.

Timotej Verbovsek, Miran Veselic. 2008. Factors influencing the hydraulic properties of wells in dolomite aquifers of Slovenia. Hydrogeology Journal 16: 779-795.

Wang Changshen, Bai Haibo. 2009. Experimental Research on Porosity of Ordovician Fengfeng Formation of Lu'an Coalfield. Journal of China University of Mining \& Technology 4: 455-462.

Zhou Wanfang, Li Gongyu. 2001. Geological barrier- a natural rock stratum for preventing confined karst water from flowing into mines in North China. Environmental Geology 40 (8): 1003-1009. 